\title{
KAJIAN SEMIOTIKA PERUBAHAN MASKOT MAJALAH ANAK-ANAK 'BOBO' PADA TAHUN 1973, 2007, DAN 2009
}

\author{
Priscilia Panti Meyrina \\ Program Studi Desain Komunikasi Visual \\ Fakultas Seni Rupa ISI Yogyakarta \\ prisciliapantimeyrina@gmail.com
}

\begin{abstract}
Children's magazine, "Bobo", has been active in Indonesia for more than 40 years. During that time, this magazine interacts with the reader by its content and visual, which is suitable with them. The interaction is that its mascot, named "Bobo", always attends in the magazine to greet and communicate with readers. Each mascot certainly has a meaning that is capable of delivering brand's vision and mission. In these forty years, "Bobo" magazine already made six changes in its mascot. From that six mascots, chose three mascots, considered to represent the change in the society.

Analysis with semiotic theory did to reveal the mascot's meaning. The changes are due to the changes of target audiences' taste. The taste changes happened because of some external factors experienced by children, as "Bobo" magazine's readers. The change of trend in the way of dressing, the presence of young artists who sing children's songs, also the appearance of their idol who became a role model to the reader, can be a clue to see "Bobo" magazine readers' taste. Mascot's appearance changes in order to adapt with changes of readers' taste.

This study concludes that the mascot's changes in order to adapt with readers' taste. Meaning contained in the mascot also represents readers' condition in certain years. Children's magazine "Bobo" is a clever magazine for using a mascot that has high flexibility, so the mascot can adjust readers' and also the readers can be loyal to "Bobo".
\end{abstract}

Keywords: Children's magazine "Bobo", mascot's changes, semiotics.

Relevance to Visual Communication Design Practice: Creating design which is related to trend is the main responsibility of designer. Moreover, this study proved that a good design should be followed by trend and audience's preferences.

\section{PENDAHULUAN}

\section{A. Latar Belakang Masalah}

Majalah anak-anak 'Bobo', adalah majalah yang, sejak kedatangannya (tahun 1973), telah berperan penting dalam memberikan bacaan yang bermutu untuk anak-anak Indonesia. Selama lebih dari 40 tahun 'Bobo' berkiprah di Indonesia, majalah ini telah menjalani berbagai dinamika dengan para pembaca. Majalah yang berasal dari Belanda ini berdinamika bersama pembaca dengan cara menyuguhkan konten dan visual yang sesuai dengan pembacanya. Kesesuaian konten dan visual yang disajikan oleh 'Bobo', menjadikan majalah ini sebagai primadona dan membuat para orang tua mempercayainya sebagai bacaan untuk anak-anak mereka.

Unsur visual yang disajikan oleh majalah ini bermacam-macam bentuknya, meliputi: foto, infografis, games berbentuk gambar, peta, ilustrasi, dan komik. Unsur-usur visual ini mempunyai komposisi yang lebih banyak daripada teks pada majalah. Pembaca majalah yang berusia 6-12 tahun tentunya sangat 
menyukai bacaan dengan unsur visual yang lebih banyak. Unsur visual sangat menarik dan mudah dipahami oleh pembaca. Melihat daya tarik visual yang begitu besar, maka tak salah jika kelinci berwarna biru dengan sweater berwarna merah bernama 'Bobo' menjadi maskot yang selalu dikenang oleh pembacanya.

Majalah 'Bobo', yang memiliki slogan "Teman Bermain dan Belajar" ini, telah melakukan berbagai perubahan pada maskotnya. Bila diamati lebih lanjut, maskot 'Bobo', pada awal kehadirannya di Indonesia, berbeda dengan maskot yang sekarang. Maskot awal majalah 'Bobo' adalah seekor kelinci yang mengalami personifikasi, yaitu tubuhnya dibuat menyerupai manusia. Kelinci tersebut memakai baju layaknya manusia dan memiliki gesture tubuh yang mencerminkan seorang anak usia Sekolah Dasar yang lincah. Secara konsep, maskot ini tidak berubah, yaitu tetap menggunakan kelinci sebagai karakter. Perubahan terjadi pada kostum yang dikenakan, lebih modern dan mengikuti mode anak zaman sekarang.

Menilik pada fungsi dari majalah sebagai media transfer kebudayaan, maka perubahan maskot dan perubahan kebudayaan pada anak-anak merupakan sebuah hubungan sebab-akibat. Dalam Jurnal "Komunikator", Narwaya (2009), menyatakan bahwa media massa memiliki "penguasa" untuk menentukan setiap 'tanda', setiap 'teks', dan setiap 'bahasa' untuk disiarkan. Mengutip dari sumber yang sama, Narwaya menambahkan bahwa media massa bukanlah ruang yang netral tetapi juga terisi banyak motivasi kecenderungan yang sudah dibentuk sedemikian rupa, dan media massa seolaholah memaksa masyarakat untuk 'menelan' sesuatu yang dihadirkan oleh media massa. Dengan pola-pola seperti itu yang berkepanjangan tentunya masyarakat akan mengalami ketergantungan bahkan loyalitas pada media massa. Majalah anak-anak "Bobo" yang sudah hadir selama lebih dari empat puluh tahun pasti sudah menjadi 'candu' bagi pembacanya dan akan menurun pada generasi berikutnya.

Perubahan-perubahan pada maskot tentunya akan mengubah 'tanda' dan 'pesan' yang dibawa oleh maskot sebelumnya. Perubahan 'pesan' melalui maskot, menunjukkan ada hal yang berubah pada komunikan (pembaca). Perubahan pada maskot tersebut dapat disebabkan oleh perilaku komunikan yang berubah atau sebaliknya, maksotlah yang mempengaruhi komunikan.

Untuk memastikan penyebab perubahan tersebut, perlu dilakukan kajian semiotika. Kajian semiotika dirasa mampu untuk membedah 'tanda' yang ada pada maskot "Bobo" ini. Semiotika dapat membedah pesan verbal dan pesan visual, menentukan ikon indeks, dan simbol, mampu mengungkap makna konotasi yang terkandung dalam maskot majalah "Bobo", dan mampu mengindikasi adanya transformasi budaya yang melatarbelakangi perubahan maskot. Penelitian ini diharapkan mampu memberi petunjuk betapa pentingnya pemberian makna baru terhadap maskot sebuah majalah bagi eksistensinya di tengah masyarakat.

\section{B. Rumusan Masalah dan Tujuan Penelitian}

\section{a. Rumusan masalah:}

1. Makna apa yang terkandung dibalik maskot majalah anak-anak "Bobo" pada tahun 1973, 2007, dan 2009? 
2. Apa saja yang melatarbelakangi perubahan maskot majalah anak-anak "Bobo"?

\section{b. Tujuan Penelitian:}

Penelitian ini bertujuan untuk mendeskripsikan perubahan maskot dan mengungkap makna yang terkandung dalam maskot majalah anak-anak "Bobo" menurut teori semiotika Charles Sanders Pierce, dan Roland Barthes.

\section{Teori dan Metode}

\section{a. Teori:}

\section{Maskot}

Maskot sejatinya merupakan sebuah pencitraan sebuah perusahaan dan mampu menampilkan citra baik perusahaan. Selain menjadi sebuah pencitraan bagi perusahaan, maskot dirasa mampu untuk menjadi sosok yang menggambarkan ciri khas dan membawa keberuntungan bagi perusahaan. Maskot 'Bobo' merupakan personifikasi dari binatang kelinci. Personifikasi ini disebut anthropomorphic atau pemberian sifat dan perilaku yang hanya dimiliki oleh manusia kepada binatang, benda mati, fenomena alam, dan hal-hal lain selain manusia. Anthropomorphic ini lebih mengedepankan fantasi dalam menciptakan karakter. Karakter yang diangkat (berupa hewan yang “dimanusiakan") ini seakan-akan mengedepankan imajinasi tingkat tinggi, karena hewan dapat berinteraksi layaknya manusia. Dalam pembedahan makna, maka penulis juga mencari beragam makna yang terkandung dalam hewan, makna pakaian, dan pencarian makna dalam tubuh sebagai referensi dalam proses penelitian.

\section{Desain}

Teori desain ini terdiri dari teori warna dan teori tipografi. Warna digunakan untuk mengidentifikasikan dan mencari makna yang terkandung dalam berbagai warna tertentu. Begitu juga dengan tipografi yang mempunyai makna di balik setiap jenis huruf. Tipografi sejatinya merupakan ungkapan visual dalam bentuk verbal. Ungkapan visual ini didapatkan karena dalam karya Desain Komunikasi Visual, sering terdapat huruf yang dibentuk sedemikian rupa untuk menyampaikan pesan lebih mendalam, biasanya karya dalam bentuk poster. Sama seperti warna, setiap jenis huruf pasti memiliki karakter yang tersimpan dalam lekuk tubuh huruf. Beragam jenis huruf ini mampu menyampaikan bagaimana dan ungkapan seperti apa yang akan disampaikan.

\section{Semiotika}

Secara etimologis, semiotika berasal dari Bahasa Yunani yang berarti tanda. Semiotika adalah ilmu yang mempelajari tanda (sign), berfungsinya tanda, dan produksi tanda. Semiotika, yang biasanya didefinisikan sebagai pengkajian tanda-tanda (the study of signs), pada dasarnya merupakan sebuah studi atas kode-kode, yaitu sistem apapun yang memungkinkan kita memandang entitasentitas tertentu sebagai tanda-tanda atau sebagai sesuatu yang bermakna (Scholes, 1982: ix dalam Budiman, 2011:3). Semiotika digunakan untuk mengungkap makna yang terkandung dalam maskot majalah anak-anak "Bobo" menurut teori semiotika Charles Sanders Pierce, dan Roland Barthes. Charles Sanders Pierce akan digunakan untuk menemukan ikon, indeks, dan simbol yang 
ada pada maskot. Sedangkan teori semiotika Roland Barthes akan membongkar makna konotasi dibalik maskot majalah "Bobo". Makna konotasi ini akan dianalisis dengan teori lima kisi-kisi kode milik Roland Barthes. Lima kisi-kisi tersebut merupakan kode simbolik, kode hermeneutik, kode narasi, kode semantik, dan kode kebudayaan.

\section{b. Metodologi}

Penelitian ini menggunakan metodologi penelitian kualitatif. Penelitian kualitatif merupakan penelitian yang data penelitian akan sepenuhnya dikendalikan oleh peneliti, dengan pola pikir keberagaman tidak keseragaman dan biasanya digunakan untuk menganalisis ilmu sosial.

\section{Populasi}

Selama empat puluh tahun, maskot majalah "Bobo" telah berubah selama enam kali. Jumlah maskot yang berubah sebanyak enam kali ini merupakan data kuantitatif yang akan dijadikan jumlah data yang ada di lapangan. Selanjutnya maskot ini tetap akan dianalisis secara kualitatif.

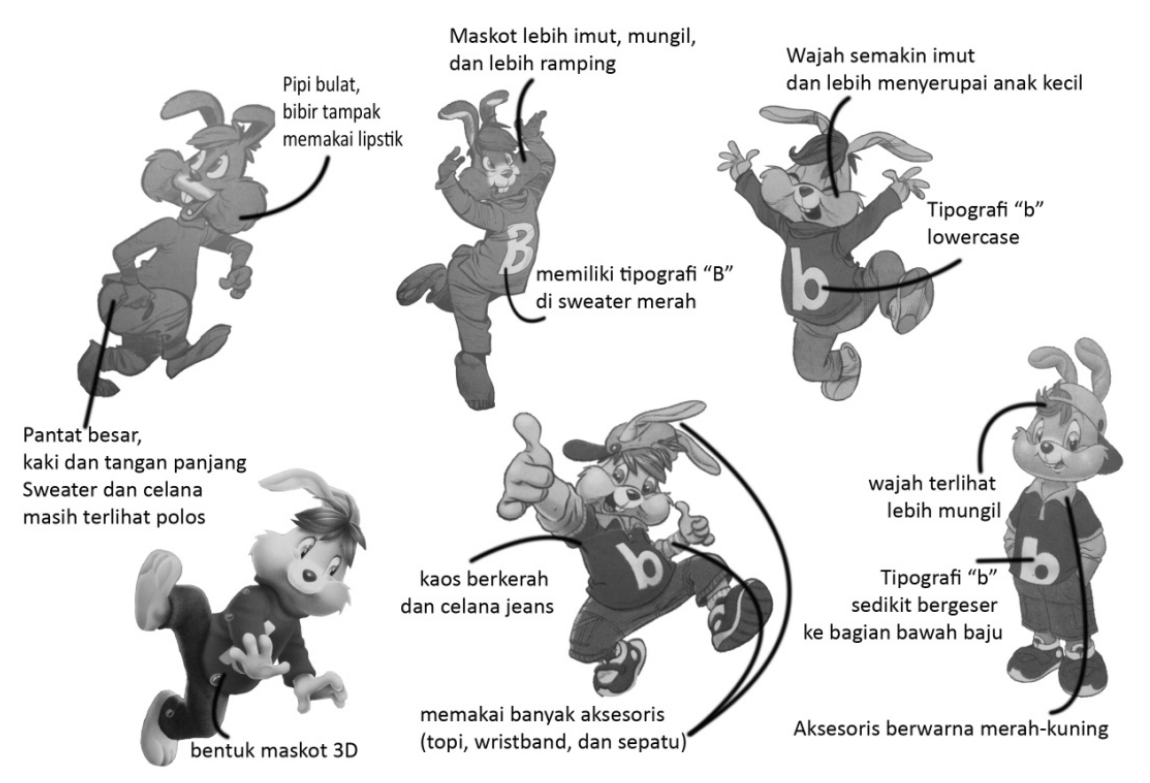

Gambar 1 Populasi Maskot Majalah "Bobo"

(Sumber: Priscilia Panti Meyrina)

\section{Sampel}

Pengambilan sampel yang hanya berdasarkan kriteria tertentu dengan berbagai alasan sering juga dinyatakan sebagai criterion-based selection daripada probability sampling. Untuk mencari makna konotasi dan faktor yang melatarbelakangi perubahan maskot, maka peneliti memilih maskot sebagai sampel dengan kriteria: penggambaran maskot dengan gaya dua dimensi, pakaian yang dipakai oleh maskot terlihat berbeda (sweater merah polos, sweater merah dengan tipografi "b", dan kaos berkerah), warna baju maskot yang menggunakan warna primer, mimik muka ceria, dan menggunakan time sampling untuk menunjukkan rentang waktu perubahan maskot. 

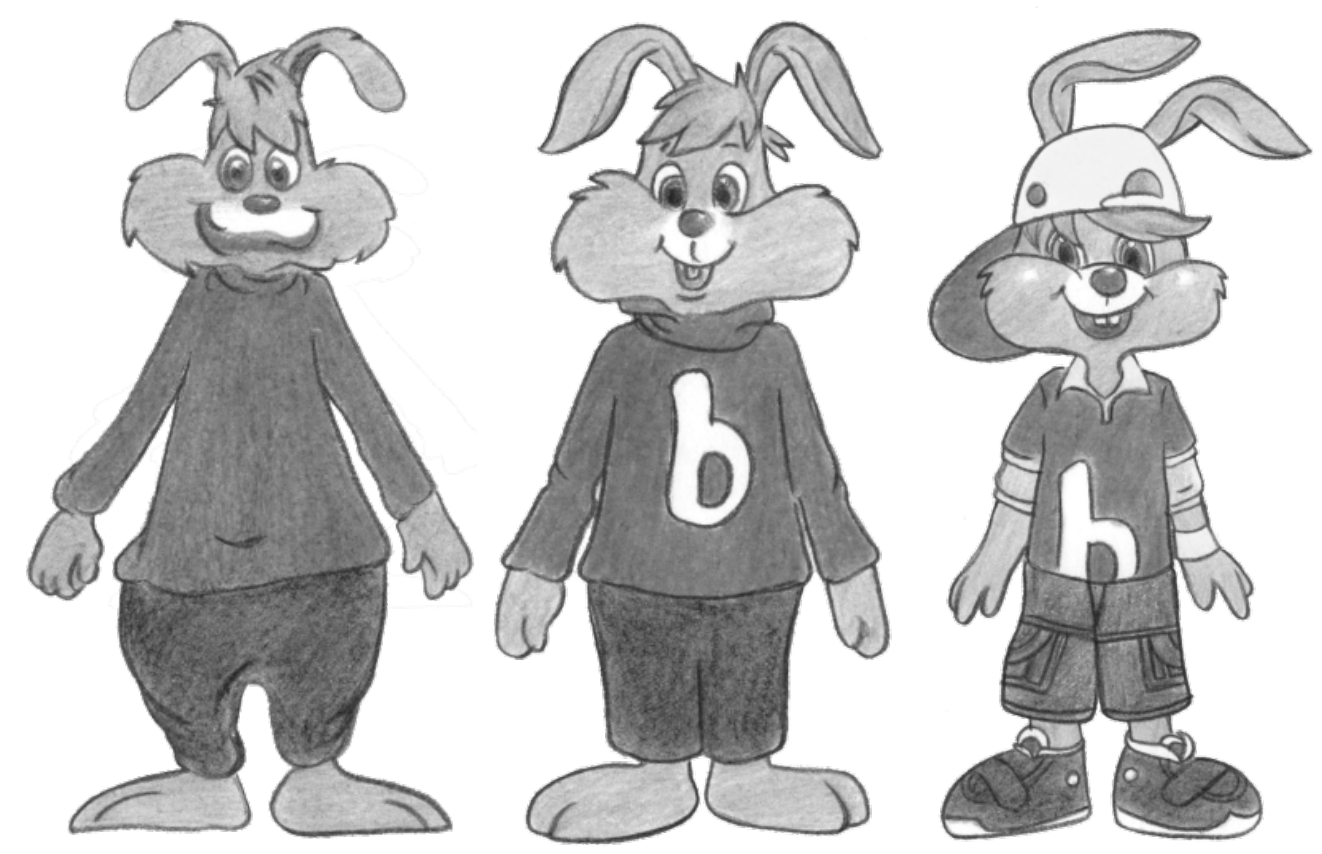

Gambar 2 Sampel Maskot yang Menjadi Objek Penelitian (Sumber: Priscilia Panti Meyrina)

\section{PEMBAHASAN}

\section{A. Kelinci Sebagai Maskot}

Majalah anak-anak "Bobo" memiliki ciri khas yaitu karakter yang berbentuk seekor kelinci. Kelinci tersebut bernama "Bobo" sama seperti nama majalah yang menggunakannya sebagai maskot. "Bobo" ini mengalami personifikasi (anthropomorphic) dan digambarkan sebagai anak laki-laki yang berusia 10 tahun yang aktif, ceria, dan pintar. Karakter ini selalu hadir di setiap edisi majalah "Bobo", baik dalam sampul (cover), sebagai ilustrasi pengisi halaman rubrik majalah, bahkan juga memiliki rubrik khusus berjudul "Bobo Kelinci dan keluarganya yang riang gembira" pada tahun 1973, sekarang rubrik ini berganti nama menjadi "Cerita bergambar Keluarga Bobo".
Maskot "Bobo" dengan bentuk tubuhnya yang kelinci ini membantu target audience majalah untuk semakin mengenal majalah dan maskot. Sebuah penelitian berjudul "Anthropomorpic animal mascot in advertising-how do consumers respond?” milik Paul Chonnel, menyatakan bahwa antropomorpic digunakan untuk menarik konsumen lebih banyak dalam memilih produk. Selain menggunakan bentuk hewan, sifat dan tingkah laku yang menyerupai manusia ini juga menjadi pertimbangan konsumen dalam melihat brand daripada brand yang tidak menggunakan maskot dalam bentuk non anthropomorphic. Maka, tepatlah majalah "Bobo" memiliki maskot dengan gaya anthropomorphic. 


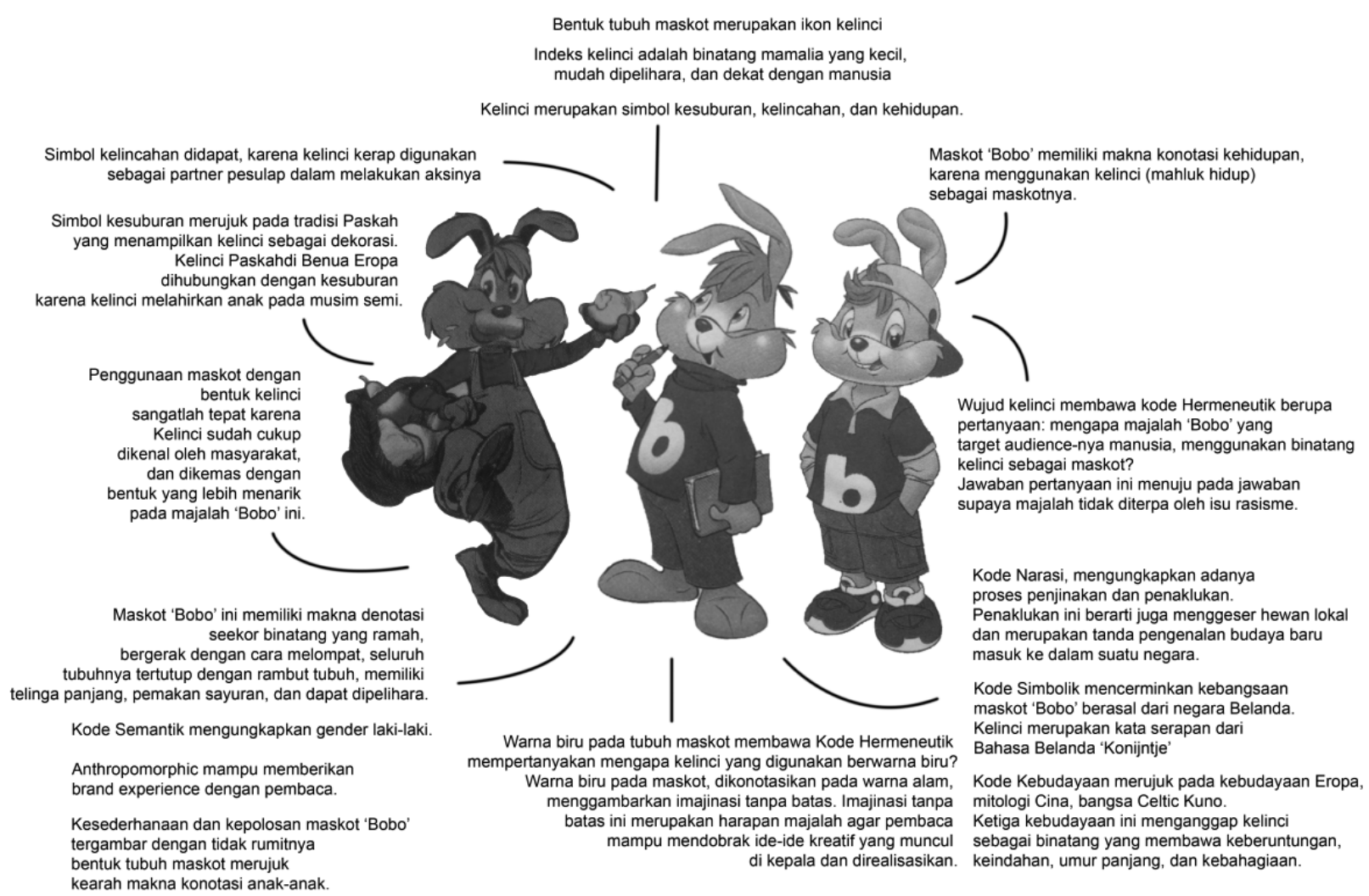

Gambar 3 Skema Semiotika Kelinci sebagai Maskot

(Sumber: Priscilia Panti Meyrina)

\section{B. Maskot Periode Pertama (1973)}

Pada maskot periode pertama, maskot tampak sangat sederhana, bertelanjang kaki, dengan tubuh dan dandanan yang mirip dengan badut. Hal ini menunjukkan bahwa pada masa itu (1973-1975) anak-anak berpenampilan sederhana tanpa banyak aksesoris yang digunakan dalam kegiatan sehari-hari. Banyaknya anak-anak yang bermain di tanah lapang, membuat maskot tidak menggunakan alas kaki untuk menandakan bahwa maskot juga suka bermain di tanah lapang. Majalah anak-anak yang hadir pada masa itu juga berpenampilan sederhana.

\section{a. Analisis Semiotika}




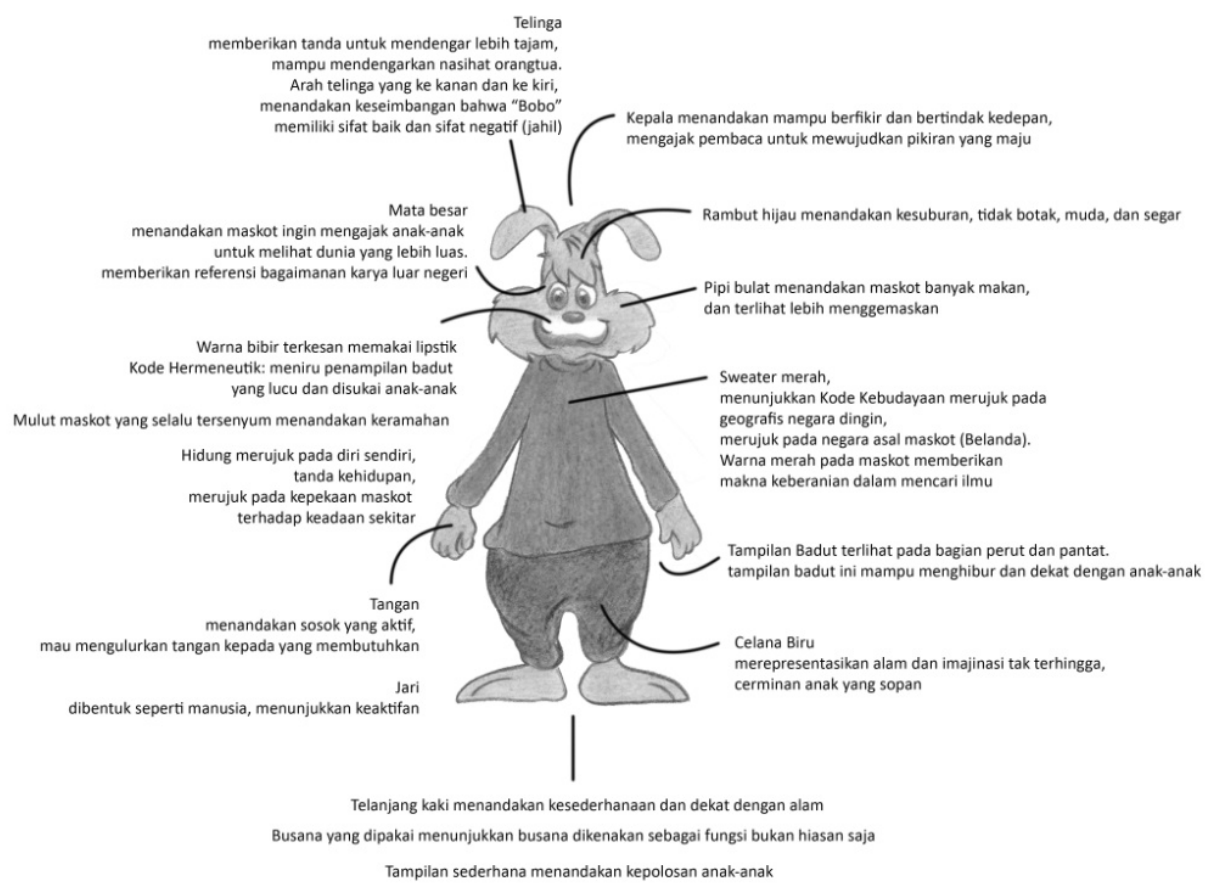

Gambar 4 Skema Semiotika Maskot Periode Pertama (Sumber: Priscilia Panti Meyrina)

b. Media dan Anak-anak pada Era Maskot

\section{Periode Pertama}

1. Anak SD sangat mudah terpengaruh oleh keadaan di sekitarnya. Mereka cenderung memperhatikan, menyerap, dan meniru apa pun yang mereka lihat dalam kehidupan mereka sehari-hari.

2. Tahun 1973, pembangunan di negara Indonesia mengalami pemulihan, demikian juga dengan estetika. Hal ini menegaskan bahwa budaya pop mulai masuk ke Indonesia. Tak heran ketika mulai bermunculan artis-artis cilik menyanyikan lagu yang ditujukan untuk anak-anak.

3. Penampilan yang sederhana sesuai dengan umur membuat penampilan idola cilik ini sesuai dan tidak berlebihan. Kesederhanaan yang disajikan ini mudah diterima oleh semua kalangan.
4. Era tahun 70an ini juga diramaikan dengan majalah anak-anak lainnya seperti Ananda, Kuncung, dan Kawanku. Perbedaan majalah "Bobo" dengan yang lainnya adalah maskot yang menjadi tokoh utama dalam majalah "Bobo", majalah kompertitor tidak memiliki maskot yang sanggup menjadi teman membaca.

5. Gaya visual pada majalah era tahun 70 -an ini lebih mengutamakan ilustrasi dengan pewarnaan yang sederhana dan tidak rumit.

\section{Maskot Periode Ketiga (2007)}

Pada periode ketiga, maskot "Bobo" merupakan maskot yang paling lama dipakai oleh majalah anak-anak "Bobo". Bentuk maskot ini hadir dari tahun 1980 hingga tahun 2007. Maskot “Bobo" periode ketiga ini juga tampil sederhana, masih menggunakan 
sweater merah, celana biru, dan tanpa alas kaki. Maskot periode ketiga dapat bertahan selama dua puluh tahun dikarenakan anakanak tidak mengalami perubahan secara signifikan. Pada masa periode ketiga ini lagu anak-anak banyak hadir dan dikonsumsi oleh mereka, sehingga artis cilik jumlahnya cukup banyak dan menjadi tokoh panutan. Penampilan artis cilik yang sederhana dengan dandanan yang sesuai umurnya ini mendorong maskot untuk tampil sederhana juga. Kesederhanaan ini membuat anak-anak dari berbagai kalangan dapat menerima "Bobo". Banyaknya media yang mulai berkembang di Indonesia membuat "Bobo" juga menambah identitas tipografi " $b$ " pada sweater merahnya supaya maskot semakin dikenal dan mudah diingat.

\section{a. Analisis Semiotika}

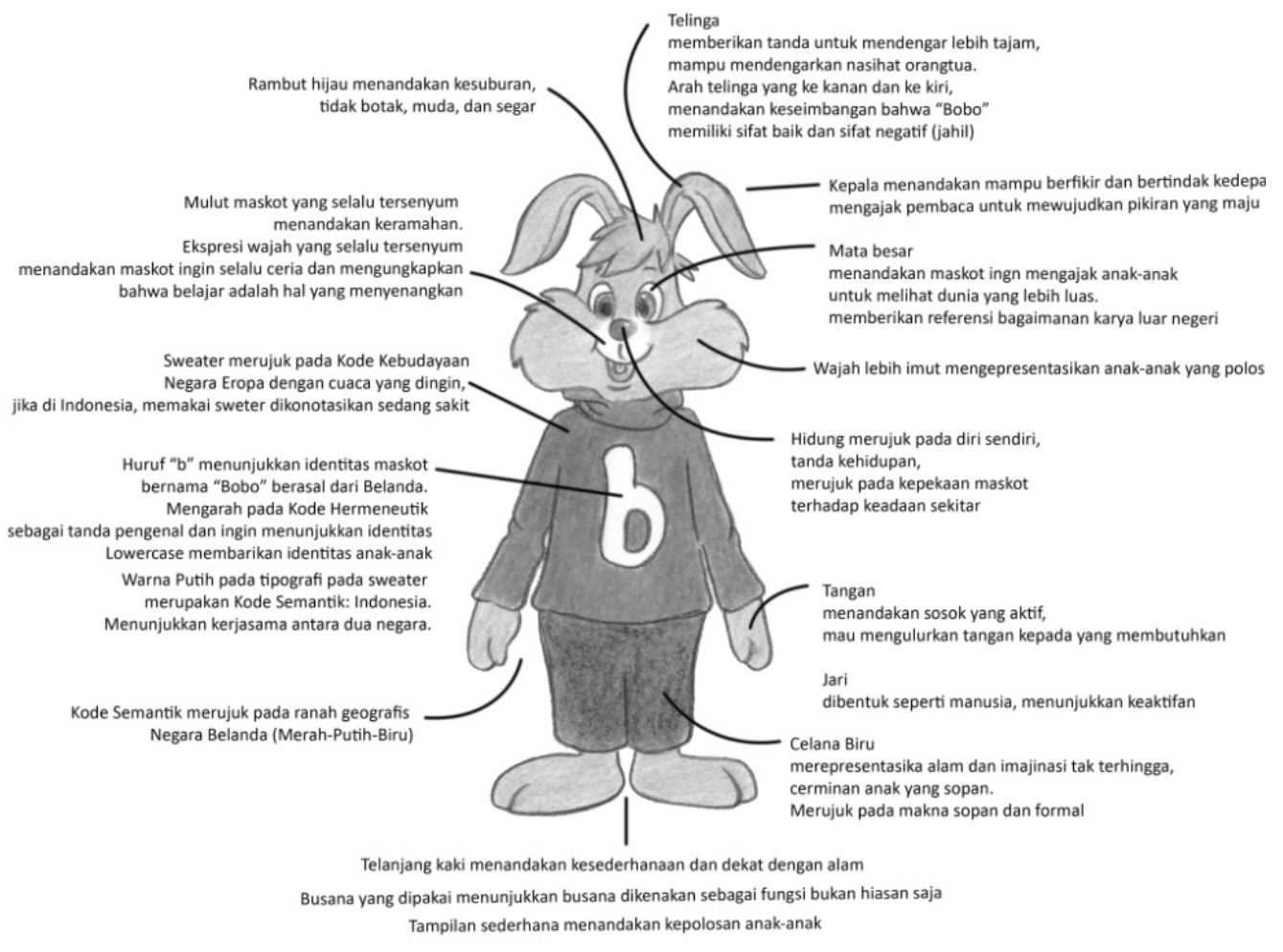

Gambar 5 Skema Semiotika Maskot Periode Ketiga (Sumber: Priscilia Panti Meyrina)

\section{b. Media dan Anak-anak pada Era Maskot}

\section{Periode Ketiga}

1. Era tahun 1980 hingga 2007 ini adalah eranya artis cilik, lebih tepatnya pada tahun 1980 hingga tahun 2000. Hadirnya artis cilik yang meramaikan dunia hiburan Indonesia ini mampu memberikan pengaruh terhadap perkembangan anak di Nusantara.

2. Artis cilik yang cukup banyak ini cukup produktif dalam memproduksi lagu anak-anak. Beragamnya lagu yang dihadirkan oleh artis cilik ini semakin memperkaya kreatifitas anak-anak dengan konten yang sesuai umur mereka. 
Artis cilik ini menjadi panutan secara serentak menjadi panutan bagi anakanak Indonesia yang mengidolakan mereka.

3. Seiring berjalannya waktu, artis cilik pun menjadi remaja dan kini telah menjadi dewasa. Minimnya generasi pengganti artis cilik menjadi tahun 2000an adalah tahun dimana merosotnya artis cilik.

4. Tahun 1980-an majalah Kuncung masih hadir, namun akhirnya tumbang juga. Majalah Kawanku kini berpindah segmen target audience yaitu menyasar para remaja.

5. Visual yang disajikan oleh majalah kompetitor ini seolah ingin menggambarkan betapa sederhananya anak-anak pada masa itu. Warna-warna yang dihadirkan kini tampak sedikit lebih 'meriah' dibandingkan dengan tahun sebelumnya.

6. Tampilan "Bobo" yang sedemikian rupa sejatinya ingin menyampaikan bahwa anak Indonesia adalah anak yang mempunyai rasa ingin tahu yang tinggi, cerdas, dan selalu ingin belajar tantang hal-hal yang baru. Dengan bertelanjang kaki, maskot juga ingin menunjukkan bahwa belajar tidak harus di dalam ruangan saja, di alampun kita bisa belajar.

\section{Maskot Periode Keenam (2009)}

Maskot pada periode keenam merupakan maskot dengan aksesoris paling banyak dan sangat terlihat modern. Aksesoris yang dikenakan oleh maskot berupa topi, wristband, celana jeans, dan sepatu. Aksesoris yang banyak ini menggambarkan maskot berasal dari kalangan menengah ke atas, karena aksesoris-aksesoris yang dikenakan merupakan item yang mampu dibeli oleh kalangan dengan sosial ekonomi menengah ke atas. "Bobo" yang ingin tampil sesuai dengan penampilan dan selera pembaca ini, mulai mengganti pakaian yang dipakai oleh maskot. Sebagai maskot yang konsumennya hidup di negara tropis, maskot mulai menyesuaikan penampilan dengan memakai pakaian yang sering dipakai oleh anak-anak Indonesia yaitu kaos berkerah.

Tampilnya maskot dengan beragam aksesoris ini menunjukkan selera anak-anak yang berubah seturut dengan adanya idola cilik baru yang muncul di tengah masyarakat. Dapat dikatakan bahwa berubahnya penampilan maskot karena ada Moment of truth yang terjadi di masyarakat pada umumnya dan anak-anak pada khususnya. Moment of truth pada masa itu adalah mulai muncul kembali idola cilik yang hadir di masyarakat dan serentak menjadi idola semua anak. Idola cilik kini membawakan lagu dengan konten lagu orang dewasa dan dengan penampilan yang sangat sporty tidak seperti idola cilik pada masa sebelumnya. Tampilan sporty ini seperti tampilan grup penyanyi "Coboy Junior" yang sedang digandrungi oleh anak-anak Indonesia. Melihat hal itu, majalah anak-anak "Bobo" dengan gesit merubah pakaian seperti idola anak-anak agar tidak dianggap "kuno" oleh pembaca dan pembaca tidak berpaling ke majalah lain.

\section{a. Analisis Semiotika}




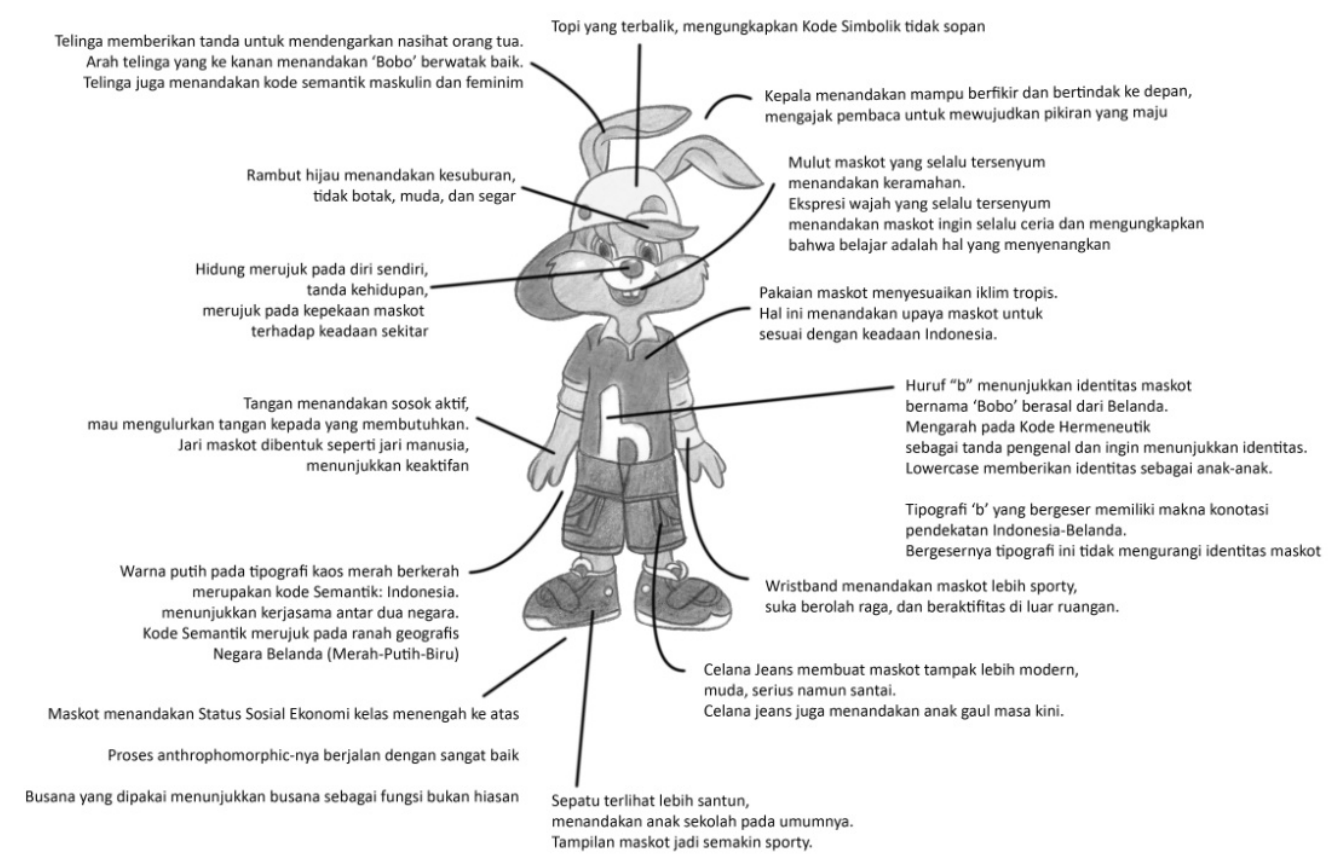

Gambar 6 Skema Semiotika Maskot Periode Keenam (Sumber: Priscilia Panti Meyrina)

\section{b. Media dan Anak-anak pada Era Maskot}

\section{Periode Keenam}

Tahun 2009 ini, dapat dilihat bahwa tampilan visual hampir semua majalah anak-anak semakin modern dan menggunakan gaya desain yang lebih pop.

1. Kewajaran tersebut dikarenakan oleh penampilan anak-anak pada era tahun 2009 dan seterusnya juga mengenakan pakaian seperti itu. Perubahan ini juga didukung dengan penampilan para artis yang kerap kali mengenakan baju yang sedikit terbuka.

2. Majunya teknologi yang dapat mengakses berbagai informasi di belahan dunia, mampu memberikan dampak yang sangat besar. Pada tahun 2009, banyak artis yang mengenakan busana dengan style kebarat-baratan. Style ini terkadang tidak sesuai dengan budaya timur seperti di Indonesia dan terkesan sexy.
3. Selain pengaruh visual yang mempengaruhi, lirik lagu yang populer pada tahun 2009 dan seterusnya juga terkesan lebih dewasa karena menggunakan kata-kata yang "vulgar" bagi anak-anak. Lagu yang berlirik "vulgar" ini lebih digemari anak-anak, karena lagu anak-anak sendiri sudah tidak ada.

\section{KESIMPULAN}

Penelitian ini telah menemukan jawaban atas makna maskot majalah anak-anak "Bobo" tahun 1973, 2007, dan 2009 yaitu: setiap periode maskot memiliki makna yang berbeda dan mampu merepresentasikan keadaan trend dan selera pembaca majalah anak-anak "Bobo". Dengan teori semiotika Ikon, Indeks, Simbol Charles S. Pierce dan Kisi lima kode milik Roland Barthes, peneliti mampu menemukan makna yang terkandung dalam maskot. 
Maskot "Bobo" dikemas dengan apik untuk dapat berkomunikasi dengan pembacanya. Penggambaran maskot dengan gaya anthropomorphic merupakan strategi visual yang dilakukan oleh majalah anak-anak "Bobo" untuk menciptakan kedekatan antara pembaca dengan majalah. Kedekatan dengan pembaca yang menimbulkan ikatan emosional ini dapat menumbuhkan loyalitas pembaca sehingga majalah"Bobo" dapat bertahan hingga lebih dari empat puluh tahun di Indonesia.

Selain mengungkap makna di balik maskot majalah "Bobo", penelitian ini juga dapat mengungkap hal-hal apa saja yang mempengaruhi perubahan maskot. Hal-hal yang melatarbelakangi ini berupa kebiasaan, keadaan sosial, dan artis cilik yang menjadi idola anak-anak. Artis cilik ini merupakan patokan trend pada anak-anak di tahun 1973, 2007, dan 2009. Dapat dikatakan bahwa "Bobo" berusaha mendekati pembaca dengan melakukan koreksi di tiap periodenya. Koreksi ini dengan melihat trend yang sedang terjadi dan mengamati selera anak-anak pada masa itu. Dengan menghadirkan trend yang sedang digemari oleh anak-anak, "Bobo" menjadi tampil segar dan tidak ketinggalan zaman. Temuan-temuan dalam trend yang sedang digandrungi oleh anak-anak kemudian diaplikasikan dalam maskot "Bobo".

Majalah "Bobo" mengalami perubahan maskot dari periode ketiga hingga keenam dengan jarak waktu yang cukup dekat. Perubahan yang cukup cepat tersebut memperlihatkan kepanikan majalah "Bobo" dengan melihat trend atau selera pembaca yang sudah mulai berubah dengan cepat. Hal ini salah satunya disebabkan oleh adanya infasi dari pasar dan budaya luar. Melihat hal tersebut dapat dikatakan bahwa kebudayaan merupakan salah satu faktor penting dalam mempengaruhi selera pasar.

Majalah anak-anak "Bobo" merupakan majalah yang cerdik dalam mengikat pembacanya. Majalah "Bobo" dikatakan cerdik karena mampu membuat maskotnya menjadi lebih fleksibel dan dapat disesuaikan dengan trend yang berlaku dalam masyarakat. Majalah anak-anak "Bobo" cukup tekun dalam mengawal anak-anak Indonesia dengan berbagai dinamika yang terjadi. Penggambaran maskot yang disesuaikan dengan zamannya ini merupakan upaya untuk menyamakan "frekuensi" antara majalah dengan target audience. Maskot memiliki fleksibilitas untuk menyesuaikan pembaca. Strategi majalah "Bobo" yang meng-update maskot agar tidak ketinggalan zaman, merupakan strategi yang sangat bagus, sehingga "Bobo" tidak akan kehilangan pembacanya.

\section{DAFTAR PUSTAKA}

[1] Budiman, Kris, 2011. Semiotika Visual Konsep, Isu, dan Problem Ikonitas. Yogyakarta: Jalasutra.

[2] Narwaya, S.T. Tri Guntur, 2009. Kuasa Media Massa dan Problem Identitas. Yogyakarta: Jurusan Ilmu Komunikasi Universitas Muhammadiyah Yogyakarta.

[3] Sutopo, H.B, 2002. Metode Penelitian Kualitatif Dasar teori dan terapannya dalam penelitian. Surakarta: Sebelas Maret University Press.

http://www.cassknowledge.com/article/anthr opomorphic-animal-mascots-advertisinghow-do-consumers-respond (diakses $28 \mathrm{Mei}$ 2014 pukul 09:00 WIB) 